\title{
Controle de doenças foliares em trigo com equipamentos de pulverização de baixo volume de aplicação
}

\author{
Control of leaf diseases in wheat with low spray volume equipments
}

\begin{abstract}
Bruno Giacomini Sari ${ }^{\mathrm{I}^{*}}$ Maurício Silva Stefanelo ${ }^{\mathrm{I}}$ Giuvan Lenz $^{\mathrm{I}}$ Ivan Francisco Dressler da Costa ${ }^{\mathrm{I}}$ Adriano Arrué ${ }^{I}$ Guilherme Rossato Augusti ${ }^{I}$ Maiquel Pizzuti Pes ${ }^{I}$
\end{abstract}

\section{RESUMO}

A utilização de equipamentos de pulverização com menor volume de aplicação no controle de doenças é uma tendência na agricultura. Portanto, este trabalho tem por objetivo determinar a eficiencia de equipamentos com baixo volume de aplicação no controle de doenças foliares do trigo. O experimento foi conduzido em duas safras agrícolas e três cultivares no município de Santa Maria, RS. Os tratamentos constituíram-se de diferentes equipamentos de pulverização, sendo eles: pontas hidráulicas do tipo leque (XR 110015) e cone vazio sem indução

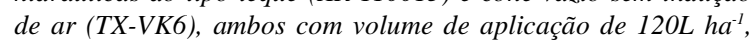
atomizadores rotativos de discos, utilizando baixo volume oleoso $\left(B V O^{\circledR}\right)$, com volumes de aplicação de $24 \mathrm{~L} \mathrm{ha}^{-1}$ e $34 \mathrm{~L} \mathrm{ha} \mathrm{C}^{-1}$ e uma testemunha sem aplicação. As gotas geradas pelos equipamentos (densidade, diâmetro mediano volumétrico) foram avaliadas através da utilização de papéis hidrosensíveis. Também foram avaliadas a severidade da mancha amarela e da ferrugem da folha. A utilização de bicos hidráulicos com volume de aplicação de $120 \mathrm{~L}$ hal apresentaram as maiores eficiências no controle das doenças. $O$ atomizador rotativo de discos com volume de aplicação de $34 \mathrm{~L}$ ha $a^{-1}$ apresentou eficiencia no controle das doenças semelhantes ao bico hidráulico. A densidade de gotas foi superior a 40 gotas $\mathrm{cm}^{-2}$ em todos os tratamentos, mesmo nos tratamentos com atomizadores rotativos de disco com baixo volume de aplicação. $O$ controle das doenças não apresentou relação direta com a cobertura mensurada pelos cartões hidrosensíveis.

Palavras-chave: atomizadores rotativos de disco, tecnologia de aplicação, densidade de gotas, manchas foliares, ferrugem da folha.

\section{ABSTRACT}

The use of spraying equipments with lower spray volume at disease control is a tendency in agriculture. The study aimed to determinate the efficiency of low spray volume at the wheat leaf diseases control. The experiment was carried during two harvest years and three cultivars in Santa Maria, RS. The treatments were constituted of different spraying equipments: hydraulic nozzle (XR 110015) and hollow cone (TX-VK6), both

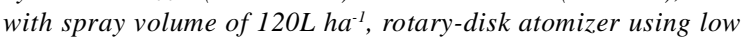
volume in oil, with spray volume of $24 \mathrm{~L} \mathrm{ha^{-1 }}$ and $34 \mathrm{~L} \mathrm{ha-1}$ and a control treatment without application. The droplets generated by the equipments (density, medium volumetric diameter) were evaluated throughout the use of water sensible cards. Also were evaluated the yellow leaf blight and leaf rust. The use of

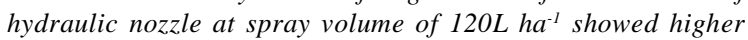
efficiency on the disease control. The rotary-disk atomizer

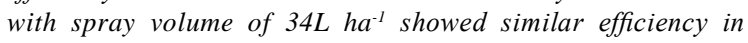
the disease control of hydraulic nozzle. The droplet density was superior to 40 droplets $\mathrm{cm}^{-2}$ in all treatments, also at the rotary-disk treatments with low pulverization rates. The disease control did not show direct relation with the coverage measured by the water sensible cards.

Key words: rotary-disk atomizer, pulverization technology, droplet density, leaf blight, leaf rust.

\section{INTRODUÇÃO}

O trigo é um dos cereais mais cultivados no mundo. No Brasil, o cereal é cultivado principalmente na região Sul. Porém, esta região caracteriza-se por apresentar um clima úmido e chuvoso, com temperaturas amenas, o que acarreta em alta incidência de doenças foliares. Entre as doenças incidentes na cultura, destacam-se as manchas foliares, causadas por Drechslera tritici-repentis, Bipolaris sorokiniana e Stagonospora nodorum; e a ferrugem da folha, causada por Puccinia triticina. As doenças causam diminuição no potencial produtivo da cultura,

IDepartamento de Defesa Fitossanitária, Universidade Federal de Santa Maria (UFSM), Av. Roraima, 1000, Cidade Universitária, 97105-900,

Santa Maria, RS, Brasil. E-mail: brunosari@hotmail.com. *Autor para correspondência. Recebido 11.02.14 Aprovado 07.04.14 Devolvido pelo autor 07.08.14 CR-2014-0206 
e sua incidência leva a perdas médias de $44,61 \%$ na produtividade (PICININI \& FERNANDES, 1995).

O controle desses patógenos pode ser feito através de práticas culturais como a rotação de cultura, tratamento de sementes (principalmente para manchas foliares) e cultivares menos susceptíveis à ferrugem e a manchas foliares (REIS et al., 1997). O controle químico é um método amplamente utilizado por ser uma das alternativas mais viáveis de garantir o potencial produtivo da cultura. Porém, o sucesso de uma aplicação não está relacionado simplesmente à escolha do fungicida. Fatores como a tecnologia e o momento de aplicação devem ser levados em consideração na hora de controlar as doenças, de modo que possibilite uma maior eficácia do fungicida e maximize o seu residual (REIS \& CASA, 2007).

A correta seleção de pontas de pulverização é, portanto, uma importante característica a ser observada, estando ela relacionada com a qualidade da aplicação. Segundo MATUO (2001), para que se possa erradicar ou atenuar de forma segura um determinado problema, é necessário haver uma deposição mínima de defensivos no alvo biológico. ANTUNIASSI \& BOLLER (2011) citam que a deposição das gotas está relacionada ao seu tamanho, sendo que gotas finas propiciam maior cobertura, porém apresentam maior risco de deriva.

Vários autores já estudaram a eficiência de diferentes pontas de pulverização sobre doenças em trigo (PANISSON et al., 2003; MENEGHETTI, 2006; FIALLOS et al., 2011), porém são escassos os estudos que tratam de aplicações com baixo volume de aplicação em trigo. A utilização de baixos volumes de aplicação possibilita maior eficiência operacional (ANTUNIASSI \& BOLLER, 2011) e permite uma maior competitividade agrícola e sustentabilidade ambiental (TEIXEIRA et al., 2010).

Portanto, o presente trabalho tem por objetivo determinar se pulverizações com um volume de aplicação reduzido, através do uso de atomizadores rotativos de disco, apresentam a mesma eficiência do que pulverizações realizadas com bicos hidráulicos com elevado volume de aplicação.

\section{MATERIAL E MÉTODOS}

Foram realizados ensaios em campo em duas safras de trigo, nos anos de 2009 e 2010, no município de Santa Maria - RS, em altitude de $95 \mathrm{~m}$, latitude de $29^{\circ} 42^{\prime} 52^{\prime \prime} \mathrm{S}$ e longitude de $53^{\circ}$ 44' 9" O. O solo é classificado como ARGISSOLO VERMELHO Distrófico arênico e o clima da região é subtropical úmido, classe $\mathrm{Cfa}$, conforme a classificação de Köppen.

No primeiro ano, o experimento foi realizado a campo em uma lavoura de trigo semeada com a cultivar 'Fundacep 30', enquanto que, no segundo ano, o experimento foi realizado com duas cultivares, 'Pampeano' e 'Nova Era', que foram semeadas lado a lado. Em ambos os casos, utilizouse a densidade de semeadura de 330 sementes $\mathrm{m}^{-2}$ e espaçamento entre linhas de $0,17 \mathrm{~m}$. Quatro parcelas de $14 \mathrm{~m}$ de largura por $20 \mathrm{~m}$ de comprimento foram demarcadas em cada cultivar, sendo que cada uma delas foi considerada uma repetição. A largura das parcelas correspondeu ao tamanho da barra do pulverizador.

Os tratamentos testados nos dois anos foram: T1: pontas hidráulicas do tipo leque (XR 110015) e volume de aplicação de 120 $\mathrm{L} \mathrm{ha}^{-1}$ (BL 120); T2: cone vazio sem indução de ar (TX-VK6) e volume de aplicação de 120L ha-1 (BC 120); T3: atomizadores rotativos de discos, utilizando baixo volume oleoso $\left(\mathrm{BVO}^{\circledR}\right)$, com volume de aplicação de 24L ha-1 (ARD 24); T4: atomizadores rotativos de discos, utilizando baixo volume oleoso $\left(\mathrm{BVO}^{\circledR}\right)$, com volume de aplicação de 34L ha-1 (ARD 34); e T5: testemunha sem aplicação.

Para as aplicações, utilizou-se um conjunto tratorizado constituído de um trator MF$2754 \times 2$ e um pulverizador montado, modelo Jacto ${ }^{\circledR}$ Condor AM-14, de capacidade volumétrica de 600L, operando à pressão constante de $275 \mathrm{kPa}$ para todos os equipamentos, sendo que os volumes de aplicação foram obtidos com a variação da velocidade do trator.

Os volumes de aplicação de $24 \mathrm{~L} \mathrm{ha}^{-1}$ e $34 \mathrm{~L}$ $\mathrm{ha}^{-1}$, utilizados nos atomizadores rotativos de disco, foram obtidos com o trator operando em velocidades de $6,1 \mathrm{~km} \mathrm{~h}^{-1}$ e $4,2 \mathrm{~km} \mathrm{~h}^{-1}$, respectivamente. Devido à diferença na vazão nominal das pontas, o trator também operou com velocidades distintas nos tratamentos com bicos hidráulicos: $10,4 \mathrm{~km} \mathrm{~h}^{-1}$ para a ponta tipo cone vazio e $7,1 \mathrm{~km} \mathrm{~h}^{-1}$ para a ponta tipo leque. Os atomizadores trabalharam com rotação de $3000 \mathrm{rpm}$ e foram espaçados em 1,4m na barra de pulverização, enquanto os bicos hidráulicos foram espaçados em $0,5 \mathrm{~m}$. No momento da pulverização, a barra encontrava-se a $0,5 \mathrm{~m}$ de altura em relação ao topo do dossel da cultura.

Nos dois anos agrícolas, as aplicações foram realizadas nos estádios de emborrachamento e antese, sendo que o fungicida utilizado consistiu da mistura comercial de azoxistrobina + ciproconazol $\left(60+24 \mathrm{~g}\right.$ de i.a. ha $\left.{ }^{-1}\right)$, além de óleo mineral na dose de $0,5 \%$ do volume de aplicação. No caso dos tratamentos 
com $\mathrm{BVO}^{\circledR}$, além do óleo mineral, foi utilizado óleo vegetal até completar a dose de $1 \mathrm{~L} \mathrm{ha}^{-1}$, conforme recomendação do fabricante dos atomizadores. No primeiro ano de condução do ensaio, a temperatura, umidade relativa do ar e velocidade do vento no momento das aplicações eram de $24+-5^{\circ} \mathrm{C}, 50+-3 \%$ e $2,6+-0,5 \mathrm{~m} \mathrm{~s}^{-1}$, respectivamente. No segundo ano, a temperatura foi de $20,2+-3{ }^{\circ} \mathrm{C}$, umidade de $77+-2 \%$ e velocidade do vento de $3,3+-0,5 \mathrm{~m} \mathrm{~s}^{-1}$.

Para as avaliações das gotas geradas nas aplicações, foram colocadas duas estacas com 1,0m de comprimento por repetição na entre linha da cultura, onde foram alocados cartões hidrossensíveis (horizontalmente) em duas posições em relação à cultura, correspondendo aos terços superior e médio, totalizando dois cartões por terço em cada repetição. A distância entre cartões foi ajustada conforme a altura de cada cultivar. Os cartões foram coletados logo após a pulverização e envoltos em papel alumínio de forma individual para evitar contato com a umidade. Para determinação da densidade de gotas (DG) e diâmetro mediano volumétrico (DMV), foram obtidas imagens digitais dos cartões, através de scanner com resolução de varredura de $1200 \mathrm{dpi}$, sendo, posteriormente, as imagens submetidas à análise eletrônica pelo software AgroScan ${ }^{\circledR}$.

Avaliações de severidade de mancha amarela (Drechslera tritici-repentis) e da ferrugem da folha (Puccinia triticina) foram realizadas aos sete, 14 e 21 dias após a segunda aplicação dos tratamentos. Foram estimadas a porcentagem de área foliar atacada pelos patógenos em 40 plantas por tratamento. Para a avaliação da mancha amarela, utilizou-se a escala diagramática proposta por JAMES (1971), enquanto que, para a avaliação da severidade da ferrugem da folha, a escala utilizada foi a proposta por PETERSON et al. (1948). Posteriormente, com base nos dados de severidade, calculou-se a área abaixo da curva de progresso da doença (AACPD).

A análise dos equipamentos foi realizada separadamente dentro de cada cultivar através de contrastes ortogonais. Buscou-se comparar equipamentos que utilizavam alto e baixo volume de aplicação (atomizadores x bicos hidráulicos), diferentes pontas de pulverização que utilizam alto volume de aplicação (cone $\mathrm{x}$ leque) e diferentes volumes de aplicação dos atomizadores (24L ha-1 $\left.\mathrm{x} 34 \mathrm{~L} \mathrm{ha}{ }^{-1}\right)$. Também foi realizado um contraste comparando-se os tratamentos que receberam a aplicação de fungicida e a testemunha (com controle $\mathrm{x}$ sem controle), quando se analisou a severidade da mancha amarela e da ferrugem da folha. A análise estatística foi realizada com o auxílio do programa Sisvar $^{\circledR}$ (FERREIRA, 2011).

\section{RESULTADOS E DISCUSSÃO}

O patossistema mancha amarela do trigo foi predominante nos dois anos de condução do experimento, apresentando os maiores valores de AACPD em todas as cultivares. Já a severidade da ferrugem da folha foi menor. Observou-se também que a severidade das doenças foi diferenciada em cada cultivar. Nas cultivares 'Fundacep 30' e 'Nova Era', a severidade de mancha amarela e ferrugem foram superiores do que na cultivar 'Pampeano' (Tabela 1).

A aplicação de fungicidas reduziu a severidade das doenças nas cultivares 'Fundacep 30' e 'Nova Era', não ocorrendo o mesmo na cultivar 'Pampeano'. Essa cultivar apresentou maior resistência à mancha amarela e à ferrugem da folha (Tabela 1), o que pode ter levado ela a não responder ao controle químico. TORMEN et al. (2013) relataram que esta cultivar tem elevada estabilidade de produção e capacidade de suprimir e/ou retardar a atividade da mancha amarela e da ferrugem da folha, não respondendo à aplicação de fungicidas.

A eficiência dos equipamentos de pulverização no controle das doenças foi diferenciada nos dois anos de condução do experimento. Analisando o contraste ARD x BH, observa-se que a severidade da mancha amarela e da ferrugem da folha não diferiram entre os equipamentos no primeiro ano do experimento. No segundo ano, não será realizada a comparação entre os equipamentos na cultivar 'Pampeano', pois ela caracterizou-se por não ser responsiva ao controle químico. Em relação à cultivar 'Nova Era', diferentemente da cultivar 'Fundacep 30' no primeiro ano, a eficiência no controle da mancha amarela foi inferior com a utilização do atomizador rotativo de disco, em comparação aos bicos hidráulicos (contraste ARD x BH). Quanto à ferrugem da folha, os equipamentos não diferiram entre si (Tabela 1).

É importante ressaltar que, nos dois anos de condução do experimento, a eficiência do atomizador rotativo de disco esteve relacionada com a escolha correta do volume de aplicação (contraste ARD 24 x ARD 34). A utilização deste equipamento com volume de aplicação de $34 \mathrm{~L} \mathrm{ha}^{-1}$ levou a uma redução significativa na AACPD da mancha amarela, em comparação ao volume de aplicação $24 \mathrm{~L} \mathrm{ha}^{-1}$, não havendo diferença no controle da ferrugem da folha do trigo (Tabela 1). De uma maneira geral, as pontas utilizadas nas pulverizações hidráulicas (contraste BC 120 x BL 120) comportaram-se da mesma maneira, não havendo diferença no controle das doenças na maioria dos casos. 
Ambas as pontas de pulverização apresentaram densidades de gota elevadas tanto no terço superior quanto no terço médio (Tabelas 2 e 3 ), sempre superiores ao recomendado para fungicidas sistêmicos, que é de 30 a 40 gotas $\mathrm{cm}^{-1}$ (OZEKI,
2006). Mesmo com baixo volume de aplicação, o atomizador rotativo de disco gerou elevada densidade de gotas, tanto no terço superior quanto no terço médio, sendo este valor sempre igual ou superior aos obtidos pelos bicos hidráulicos. Isso ocorre pois

Tabela 1 - Área abaixo da curva de progresso da mancha amarela e da ferrugem da folha nos dois anos de condução do experimento.

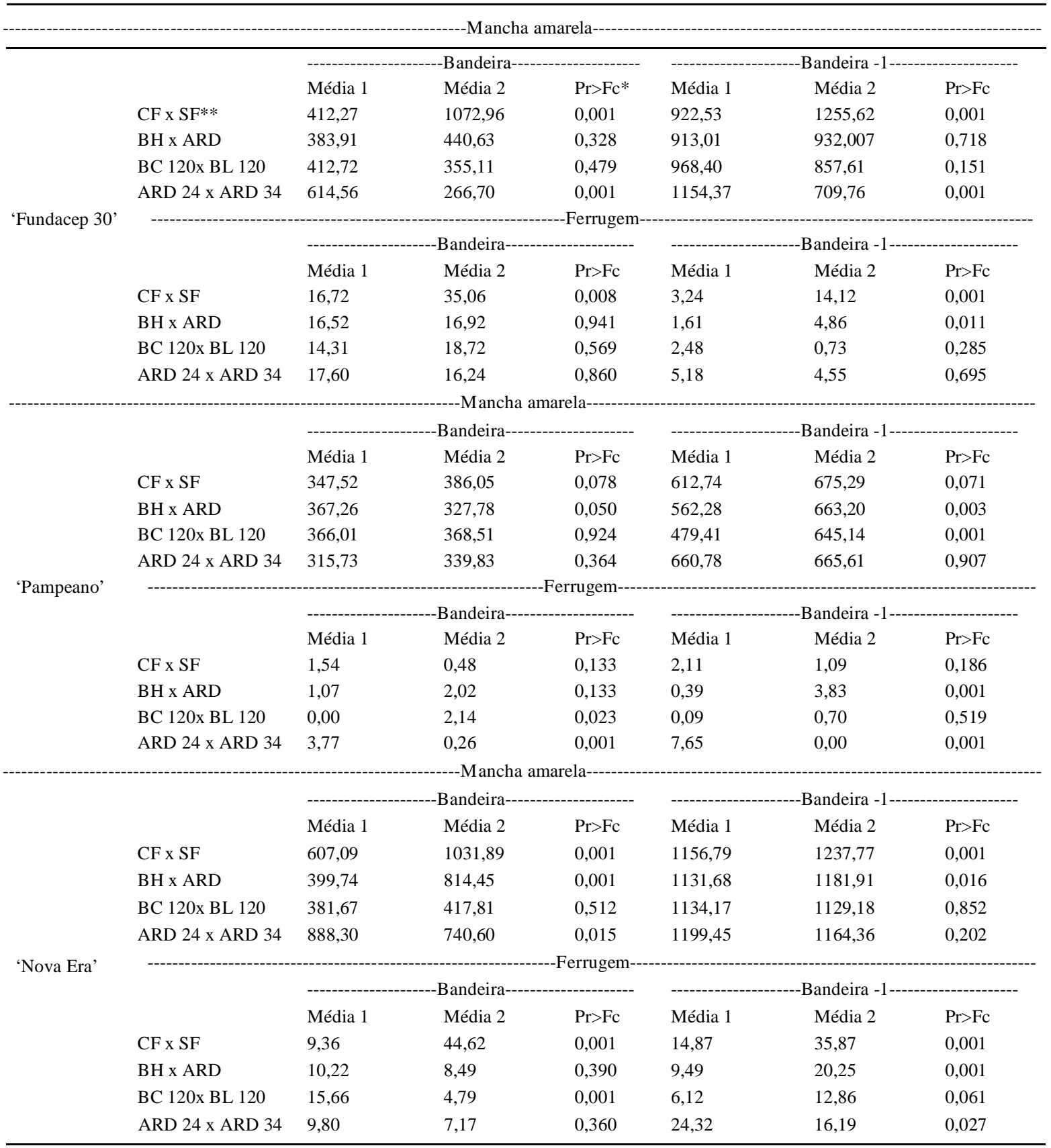

* Médias dos contrastes não diferem entre si quando $\mathrm{Pr}>\mathrm{Fc}$ for igual ou superior a $0,05 . * * \mathrm{CF}=\mathrm{Com}$ aplicação de fungicida; $\mathrm{SF}=\mathrm{Sem}$ aplicação de fungicida; BH: Bico hidráulico; ARD = Atomizadores rotativos de disco; ARD 24: Atomizadores rotativos de disco com volume de aplicação de 24L ha ${ }^{-1}$; ARD 34: Atomizadores rotativos de disco com volume de aplicação de $34 \mathrm{~L} \mathrm{ha}^{-1}$; BC 120: Bico cone vazio com volume de aplicação de $120 \mathrm{~L} \mathrm{ha}^{-1}$; BL 120: Bico leque com volume de aplicação de 120L ha-1. 
este equipamento tem como característica gerar gotas finas, que propiciam maior cobertura do alvo (Tabelas 2 e 3). Esta característica é importante, pois, quando o volume de aplicação é reduzido, maior atenção dever ser dada ao tamanho de gota, de modo que a cobertura do alvo não seja prejudicada, uma vez que, com elevados volumes, essa característica não é limitante (BOLLER et al., 2007).

Apesar da elevada densidade de gotas gerada com a utilização do atomizador rotativo de disco, não foi observado um melhor desempenho deste equipamento. Pelo contrário, a utilização do equipamento com volume de aplicação de $24 \mathrm{~L} \mathrm{ha}^{-1}$ mostrou-se ineficiente no controle das doenças. Apenas quando aumentado o volume de aplicação para 34L ha-1, observou-se uma eficiência próxima aos bicos hidráulicos com volume de aplicação de $120 \mathrm{~L} \mathrm{ha}^{-1}$. Gotas muito finas, como as geradas pelos atomizadores, podem sofrer uma maior ação de fenômenos climáticos, como temperatura e umidade

Tabela 2 - Características relacionadas com a deposição de gotas da primeira aplicação de fungicida nos terços superior e médio nos dois anos de condução do experimento.

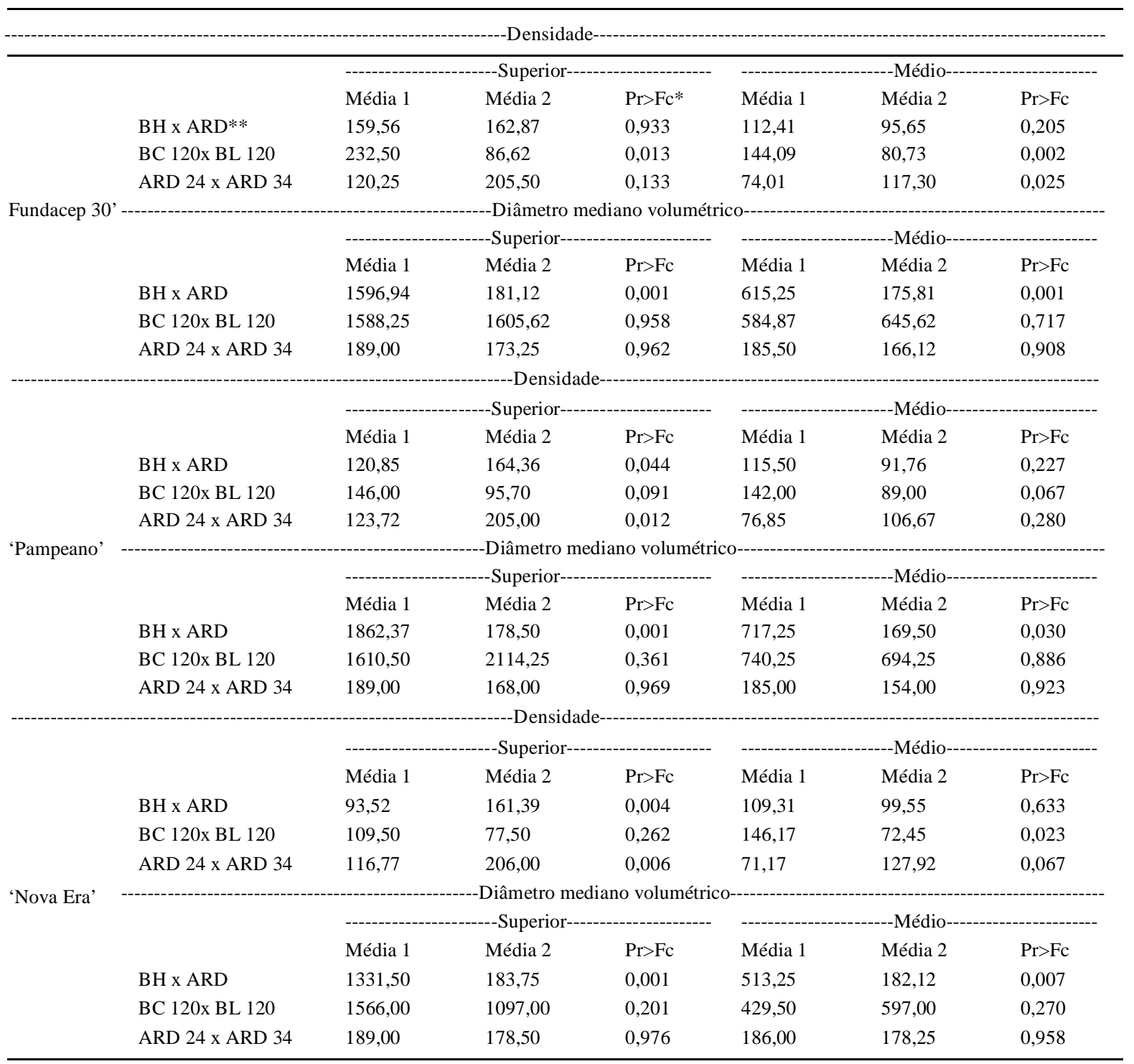

* Médias dos contrastes não diferem entre si quando $\mathrm{Pr}>\mathrm{Fc}$ for igual ou superior a 0,05. **BH: Bico hidráulico; ARD = Atomizadores rotativos de disco; ARD 24: Atomizadores rotativos de disco com volume de aplicação de 24L ha ${ }^{-1}$; ARD 34: Atomizadores rotativos de disco com volume de aplicação de $34 \mathrm{~L} \mathrm{ha}^{-1}$; BC 120: Bico cone vazio com volume de aplicação de 120L ha ${ }^{-1}$; BL 120: Bico leque com volume de aplicação de $120 \mathrm{~L} \mathrm{ha}^{-1}$. 
Tabela 3 - Características relacionadas com a deposição de gotas da segunda aplicação de fungicida nos terços superior e médio, nos dois anos de condução do experimento.

\begin{tabular}{|c|c|c|c|c|c|c|c|}
\hline \multirow{11}{*}{ 'Fundacep 30' } & & \multicolumn{3}{|c|}{ 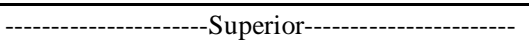 } & \multicolumn{3}{|c|}{ 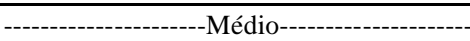 } \\
\hline & & Média 1 & Média 2 & $\operatorname{Pr}>\mathrm{Fc}^{*}$ & Média 1 & Média 2 & $\operatorname{Pr}>\mathrm{Fc}$ \\
\hline & $\mathrm{BH} \times \mathrm{ARD}^{* *}$ & 82,15 & 123,41 & 0,002 & 55,17 & 65,51 & 0,288 \\
\hline & BC $120 x$ BL 120 & 96,52 & 67,77 & 0,096 & 53,74 & 56,61 & 0,833 \\
\hline & ARD $24 \times$ ARD 34 & 135,87 & 110,90 & 0,144 & 78,01 & 53,00 & 0,075 \\
\hline & \multirow{2}{*}{\multicolumn{7}{|c|}{ - }} \\
\hline & & & & & & & \\
\hline & & Média 1 & Média 2 & $\operatorname{Pr}>\mathrm{Fc}$ & Média 1 & Média 2 & $\operatorname{Pr}>\mathrm{Fc}$ \\
\hline & $\mathrm{BH} \times \mathrm{ARD}$ & 644,87 & 228,06 & 0,001 & 375,75 & 203,12 & 0,001 \\
\hline & BC $120 x$ BL 120 & 495,62 & 794,12 & 0,002 & 295,50 & 456,00 & 0,001 \\
\hline & ARD $24 \times$ ARD 34 & 208,50 & 247,62 & 0,655 & 191,00 & 215,25 & 0,484 \\
\hline \multirow{10}{*}{ 'Pampeano' } & & \multicolumn{3}{|c|}{----------------------S Superior---------------------- } & \multicolumn{3}{|c|}{----------------------Médio-------------------- } \\
\hline & & Média 1 & Média 2 & $\operatorname{Pr}>\mathrm{Fc}$ & Média 1 & Média 2 & $\operatorname{Pr}>\mathrm{Fc}$ \\
\hline & $\mathrm{BH} \times \mathrm{ARD}$ & 87,81 & 123,62 & 0,044 & 55,25 & 69,70 & 0,182 \\
\hline & BC $120 x$ BL 120 & 108,60 & 67,02 & 0,090 & 47,87 & 62,62 & 0,326 \\
\hline & ARD $24 \times$ ARD 34 & 141,25 & 106,00 & 0,144 & 82,70 & 56,70 & 0,096 \\
\hline & & \multicolumn{3}{|c|}{ 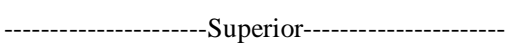 } & - & --Médio-- & 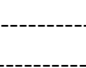 \\
\hline & & Média 1 & Média 2 & $\operatorname{Pr}>\mathrm{Fc}$ & Média 1 & Média 2 & $\operatorname{Pr}>\mathrm{Fc}$ \\
\hline & $\mathrm{BH} \times \mathrm{ARD}$ & 718,50 & 232,62 & 0,001 & 361,00 & 205,12 & 0,001 \\
\hline & BC $120 \times$ BL 120 & 581,75 & 855,25 & 0,050 & 296,00 & 426,00 & 0,027 \\
\hline & ARD $24 \times$ ARD 34 & 216,25 & 249,00 & 0,798 & 196,75 & 214,50 & 0,722 \\
\hline \multirow{10}{*}{ 'Nova Era' } & & \multicolumn{3}{|c|}{----------------------Superior---------------------- } & \multicolumn{3}{|c|}{-----------------------Médio---------------------. } \\
\hline & & Média 1 & Média 2 & $\operatorname{Pr}>\mathrm{Fc}$ & Média 1 & Média 2 & $\operatorname{Pr}>\mathrm{Fc}$ \\
\hline & BH x ARD & 76,49 & 123,20 & 0,030 & 55,10 & 61,31 & 0,728 \\
\hline & BC $120 x$ BL 120 & 84,45 & 68,52 & 0,563 & 59,60 & 50,60 & 0,721 \\
\hline & ARD $24 \times$ ARD 34 & 130,60 & 115,80 & 0,591 & 73,32 & 49,30 & 0,349 \\
\hline & & \multicolumn{3}{|c|}{-----------------------Superior---------------------- } & \multicolumn{3}{|c|}{ 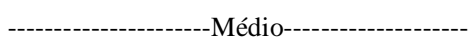 } \\
\hline & & Média 1 & Média 2 & $\mathrm{Pr}>\mathrm{Fc}$ & Média 1 & Média 2 & $\mathrm{Pr}>\mathrm{Fc}$ \\
\hline & $\mathrm{BH} \times \mathrm{ARD}$ & 571,25 & 223,50 & 0,002 & 390,50 & 201,12 & 0,001 \\
\hline & BC $120 x$ BL 120 & 409,50 & 733,00 & 0,023 & 295,00 & 486,00 & 0,002 \\
\hline & ARD $24 \times$ ARD 34 & 200,75 & 246,25 & 0,722 & 186,25 & 216,00 & 0,562 \\
\hline
\end{tabular}

* Médias dos contrastes não diferem entre si quando $\mathrm{Pr}>\mathrm{Fc}$ for superior a 0,05. ** $\mathrm{BH}$ : Bico hidráulico; ARD = Atomizadores rotativos de disco; ARD 24: Atomizadores rotativos de disco com volume de aplicação de 24L ha ${ }^{-1}$; ARD 34: Atomizadores rotativos de disco com volume de aplicação de $34 \mathrm{~L} \mathrm{ha}^{-1}$; BC 120: Bico cone vazio com volume de aplicação de $120 \mathrm{~L} \mathrm{ha}^{-1}$; BL 120: Bico leque com volume de aplicação de $120 \mathrm{~L} \mathrm{ha}^{-1}$.

relativa do ar, diminuindo o tempo de vida das gotas (BALAN et al., 2008), o que pode ter reduzido a eficiência biológica do fungicida, mesmo este equipamento gerando maior densidade de gotas em relação aos bicos hidráulicos.

Além disso, o uso de papéis hidrossensíveis apresenta algumas restrições à avaliação da pulverização. BAYER et al. (2012) observaram que o uso de cartões foi incapaz de realizar a leitura de gotas muito finas. O elevado valor de DMV observado
(Tabelas 2 e 3) também pode indicar que houve uma sobreposição de gotas, o que pode ter levado a uma subestimativa na densidade de gotas lida pelo scanner. Desse modo, a limitação dos cartões hidrossensíveis em avaliar a pulverização pode estar relacionada ao fato de não ter sido observada uma relação direta entre a densidade de gotas e o controle das doenças.

Observa-se, portanto, que a escolha correta do volume de aplicação pode ser decisiva no controle das doenças do trigo. Porém, a redução de 
volumes de aplicação é uma tendência na agricultura e justifica-se pela maior capacidade operacional do pulverizador (ROMÁN et al., 2009; MOTA, 2011), permitindo que a pulverização seja realizada durante o período com as melhores condições climáticas. Mesmo com um volume de aplicação quase quatro vezes menor, o tratamento ARD 34 apresentou eficiência muito próxima aos bicos hidráulicos. Em locais com janelas de aplicação reduzidas, a utilização de atomizadores rotativos de disco com volume de aplicação de $34 \mathrm{~L} \mathrm{ha}^{-1}$ poderia ser uma alternativa no controle de doenças do trigo, uma vez que aumentaria a capacidade operacional do pulverizador e permitiria a realização da aplicação em momentos mais adequados.

\section{CONCLUSÃO}

A utilização de bicos hidráulicos com volume de aplicação de $120 \mathrm{~L} \mathrm{ha}^{-1}$ proporcionou o maior controle da mancha amarela e da ferrugem da folha do trigo. A eficiência no controle da mancha amarela e da ferrugem da folha dos atomizadores rotativos de disco com volume de aplicação de $34 \mathrm{~L} \mathrm{ha}^{-1}$ foi próxima ao dos bicos hidráulicos, principalmente do primeiro ano de condução do experimento. $\mathrm{O}$ uso de atomizadores rotativos de disco com volume de aplicação de $24 \mathrm{~L} \mathrm{ha}^{-1}$ não é recomendável, devido à baixa eficiência no controle da mancha amarela e da ferrugem da folha do trigo.

\section{REFERÊNCIAS}

ANTUNIASSI, U.R.; BOLLER, W. Tecnologia de aplicação de fungicidas. In: ANTUNIASSI, U.R.; BOLLER, W. Tecnologia de aplicação para culturas anuais. Passo Fundo: Aldeia Norte; Botucatu: FEPAF, 2011. p.221-229.

BALAN, M.G. et al. Deposição da calda pulverizada por três pontas de pulverização sob diferentes condições meteorológicas. Semina: Ciências Agrárias, v.29, n.2, p.293-298, 2008. Disponível em: <http://www.uel.br/revistas/uel/index.php/semagrarias/article/ view/2816>. Acesso em: 30 jan. 2014.

BAYER, T. et al. Aplicação aérea de fungicidas na cultura do arroz irrigado com diferentes bicos de pulverização. Ciência Rural, v.42, n.12, p.2185-2191, 2012. Disponível em: <http://www. scielo.br/pdf/cr/v42n12/a34612cr6620.pdf>. Acesso em: 30 jan. 2014. doi: 10.1590/S0103-84782012005000114.

BOLLER, $\mathrm{W}$ et al. Tecnologia de aplicação de fungicidas - parte I. Revisão Anual de Patologia de Plantas, v.15, p.243-276, 2007.

FERREIRA, D.F. Sisvar: a computer statistical analysis system. Ciência e Agrotecnologia, v.35, n.6, p.1039-1042, 2011. Disponível em: <http://www.scielo.br/scielo.php?pid=S1413$70542011000600001 \&$ script=sci_arttext $>$. Acesso em: 10 jan. 2014. doi: doi.org/10.1590/S1413-70542011000600001.
FIALLOS, F. R. G. et al. Eficiência de fungicidas no controle de doenças foliares na cultura do trigo, em resposta à aplicação com diferentes pontas de pulverização. Scientia Agropecuaria, v.2, n.4, p. 229-237, 2011. Disponível em: <http://dialnet.unirioja.es/servlet/ articulo?codigo=3810329>. Acesso em: 29 ago. 2013.

JAMES, W.C. An illustrated series of assessment keys for plant diseases, their preparation and usage. Canadian Plant Disease Survey, v.51, n.2, p.39-65, 1971.

MATUO, T. et al. Tecnologia de aplicação de defensivos agrícolas e equipamentos e técnicas de aplicação. In: ABEAS. Curso de proteção de plantas, Mod. 2, especialização por tutoria à distância. Brasília: ABEAS, 2001. p.71.

MENEGHETTI, R.C. Tecnologia de aplicação de fungicidas na cultura do trigo. 2006. 57f. Dissertação (Mestrado em Agronomia) - Programa de Pós-graduação em Agronomia, Universidade Federal de Santa Maria, RS.

MOTA, A.A.B. Quantificação do ar incluído e espectro de gotas de pontas de pulverização em aplicações com adjuvantes. 2011. 73f. Dissertação (Mestrado em Agronomia) - Programa de Pósgraduação em Agronomia - Energia na Agricultura, Universidade Estadual Paulista “Júlio de Mesquita Filho", SP.

OZEKI, Y. Manual de aplicação aérea. São Paulo: Edição do Autor, 2006. 101p.

PANISSON, E. et al. Técnicas de aplicação de fungicida em trigo para o controle de giberela (Gibberella zeae). Ciência Rural, v.33, n.1, p.13-20, 2003. Disponível em: <http://www.scielo.br/ pdf/cr/v33n1/14137.pdf>. Acesso em: 21 set. 2013. doi: 10.1590/ S0103-84782003000100003.

PETERSON, R.F et al. A diagrammatic scale for rust intensity on leaves and stems of cereals. Canadian Journal of Research, v.26, p.496-500, 1948. Disponível em: <http://www.nrcresearchpress.com/doi/pdf/10.1139/ cjr48c-033>. Acesso em: 03 set. 2013. doi: 10.1139/cjr48c-033.

PICININI, E.C.; FERNANDES, J.M.C. Efeito de diferentes fungicidas sobre o rendimento de grãos, sobre o peso do hectolitro e sobre o controle da ferrugem da folha (Puccinia recondita f.sp. tritici) em trigo, cultivar BR 43. Fitopatologia Brasileira, v.20, p.319, 1995.

REIS, E.M. et al. Doenças do trigo. In: KIMATI, H. et al. (Org.). Manual de fitopatologia. Volume 2: doenças em plantas cultivadas. São Paulo: Ceres, 1997. p.88-102.

REIS, E.M.; CASA, R.T. Doenças dos cereais de inverno: diagnose, epidemiologia e controle. 2.ed. Rev. Atual. Lages: GraPHel, 2007. 176p.

ROMÁN, R.A.A. et al. Cobertura da cultura da soja pela calda fungicida em função de pontas de pulverização e volumes de aplicação. Scientia Agraria, v.10, n.3, p.223-232, 2009.

TEIXEIRA, E.S. et al. Uso de baixo volume oleoso e assistência de ar no controle de plantas daninhas. Semina: Ciências Agrárias, v.31, supl.1, p.1229-1234, 2010. Disponível em: <http://www.uel. br/revistas/uel/index.php/semagrarias/article/view/2930/6922>. Acesso em: 16 set. 2013.

TORMEN, N.R. et al. Reação de cultivares de trigo à ferrugem da folha e mancha amarela e responsividade a fungicidas. Ciência Rural, v.43, n.2, p. 239-246, 2013. Disponível em: <http://www. scielo.br/pdf/cr/v43n2/a4513cr5107.pdf >. Acesso em: 20 set. 2013. doi: 10.1590/S0103-84782013000200008. 